James B. Eisenkraft MB MRCP FFARCS,

W. Jeffrey Book MD FRCPC, Angelos E. Papatestas MD*

\title{
Sensitivity to vecu- ronium in myasthenia gravis: a dose-response study
}

A cumulative dose plus infusion technique and integrated EMG monitoring of the first dorsal interosseous muscle were used to determine the potency of vecuronium in 20 normal patients and in ten patients with myasthenia gravis under thiamylal, $\mathrm{N}_{2} \mathrm{O}, \mathrm{O}_{2}$, fentanyl anaesthesia. The mean ( $\pm S E M)$ values for $E D_{50}, E D_{90}$, and $E D_{95}$ in the normal patients were $19 \pm 1,31 \pm 1$ and $36 \pm 2$ $\mu \mathrm{g} \cdot \mathrm{kg}^{-1}$, respectively. Myasthenic patients showed increased sensitivity to vecuronium, the mean values for $E D_{50}, E D_{90}$, and $E D_{95}$ were $10 \pm 2,17 \pm 2$ and $20 \pm 3 \mu \mathrm{g} \cdot \mathrm{kg}^{-1}$, being 50,55 and 56 per cent of normal, respectively. We did not demonstrate a difference in sensitivity to vecuronium between those myasthenic patients who received pyridostigmine preoperatively and those who did not, nor among those chronically treated with corticosteroids, compared with those who were not.

Une dose cumulative plus une technique de perfusion et une surveillance électromographique intégrée du muscle interosseux dorsal fut utilisée afin de déterminer la puissance du vécuronium chez 20 patients normaux et chez dix patients atteints de myasthénie grave sous thiamylal, $\mathrm{N}_{2} \mathrm{O}, \mathrm{O}_{2}$, et fentanyl. Les valeurs moyennes ( $\pm S E M$ ) du $E D_{50} . E D_{90}$ et $E D_{9 s}$ chez les patients normaux étaient de $19 \pm 1,31 \pm 1$ et 36 $\pm 2 \mu \mathrm{g} \cdot \mathrm{kg}^{-1}$ respectivement. Les patients myasthéniques ont

\section{Key words}

COMPLICATIONS: myasthenia gravis;

NEUROMUSCULAR RELAXANTS: vecuronium;

MEASUREMENT TECHNIQUES: electromyography, neuromuscular blockade.

From The Departments of Anesthesiology and Surgery, Mount Sinai School of Medicine of the City University of New York, New York, NY 10029-6574.

Address correspondence to: Dr. J.B. Eisenkraft, Department of Anesthesiology, Box 1010, The Mount Sinai Hospital, One Gustave L. Levy Place, New York, NY 10029 6574, Telephone (212) 241-7467.

This work was presented, in part, at the Annual Meeting of the International Anesthesia Research Society, Orlando, Florida in March 1989.

*Dr. Papatestas died suddenly on February 12, 1989. démontré une augmentation de la sensitivité au vécuronium, les valeurs movennes de la $E D_{50}, E D_{90}$ et $E D_{95}$ furent $10 \pm 2,17 \pm$ 2 et $20 \pm 3 \mu \mathrm{g} \cdot \mathrm{kg}^{-l}$ étant respectivement 50,55 et 56 pour cent de la normale. On n'a pas démontré de différence avec les patients avant reçu de la pyridostigmine en période préopératoire et ceux qui n'en n'ont pas reçue, de même qu' on n' en a pas trouvé avec ceux qui étaient traités aux corticostéroides comparé à ceux qui ne l'étaient pas.

Patients with myasthenia gravis are known to be sensitive to the neuromuscular blocking effects of nondepolarizing muscle relaxants. ${ }^{1,2}$ Vecuronium has a shorter duration of action than either d-tubocurarine or pancuronium in normal patients and has been successfully used to produce controlled neuromuscular blockade in patients with myasthenia gravis. ${ }^{3-7}$ To date, only one study, which used a cumulative dose administration technique, has provided pharmacodynamic data on the sensitivity to vecuronium in myasthenic patients. ${ }^{5}$ The cumulative dose technique has been shown to underestimate the potency of vecuronium in normal patients, ${ }^{9-11}$ whereas the use of a cumulative dose plus infusion technique provides potency estimates which are similar to those obtained using a single bolus technique. ${ }^{8}$

The purpose of the present study was to use a cumulative dose plus infusion technique: (1) to establish the dose-effect relationship for vecuronium in normal patients and patients with myasthenia gravis, and (2) in patients with myasthenia gravis, to determine whether administration of pyridostigmine on the morning of surgery, or chronic corticosteroid therapy, would influence the sensitivity to vecuronium.

\section{Methods}

Twenty normal patients and ten patients with myasthenia gravis gave their written informed consent to participate in this institutionally approved study. The normal controls were randomly selected ASA physical status I patients, free from medications or conditions known to affect neuromuscular function, and scheduled to undergo gyn- 
TABLE I Demographic data - myasthenic patients

\begin{tabular}{|c|c|c|c|c|c|c|c|c|c|c|c|}
\hline Parient number & $I$ & 2 & 3 & 4 & 5 & 6 & 7 & 8 & 9 & 10 & $M e a n \pm S D$ \\
\hline Sex & $F$ & $\mathbf{F}$ & $F$ & $\mathbf{F}$ & $\mathbf{F}$ & $\mathbf{F}$ & $\mathbf{F}$ & $\mathrm{F}$ & $\mathbf{M}$ & $\mathbf{F}$ & - \\
\hline Age $(y r)$ & 37 & 49 & 34 & 43 & 52 & 63 & 25 & 21 & 66 & 22 & $41 \pm 16$ \\
\hline Weight (kg) & 66 & 80 & 41 & 80 & 70 & 79 & 60 & 60 & 75 & 53 & $66 \pm 13$ \\
\hline MG class & IIB & IV & IV & IIB & IV & IIA & IIB & IIA & IIB & IIB & - \\
\hline Pyridostigmine (mg $\cdot$ day $\left.^{-1}\right)$ & 180 & 360 & 210 & 345 & 540 & 240 & 300 & 240 & 225 & 360 & $300 \pm 106$ \\
\hline Pyridostigmine preop & No & Yes & Yes & No & No & Yes & No & No & No & Yes & - \\
\hline Duration of discase (mo) & 36 & 204 & 84 & 5 & 420 & 100 & 84 & 41 & 8 & 4 & $99 \pm 128$ \\
\hline Steroid dose (mg) & No & No & $15 \mathrm{mg}$ QOD & No & No & No & 30 QOD & No & No & 40/20 Alt. days & - \\
\hline Steroids preop & No & No & Yes & No & No & No & Yes & No & No & Yes & 一 \\
\hline
\end{tabular}

TABLE II Demographic Data - Normal Patients

\begin{tabular}{ll}
\hline$n=20$ & Mean $\pm S D$ \\
\hline Males/females & $4 / 16$ \\
Weight (kg) & $59 \pm 20$ \\
Age & $38.5 \pm 13.2$ \\
ASA physical status & All ASA I \\
\hline
\end{tabular}

aecological or orthopaedic surgical procedures. The myasthenic patients were ASA physical status II or III, Osserman Class IIA-IV, ${ }^{12}$ and scheduled to undergo transcervical thymectomy as a surgical treatment for their myasthenia. ${ }^{13}$ The patient demographic data are shown in Tables I and Il. Although both groups were studied concurrently, patients were not age or sex matched. All of the myasthenic patients were being treated with pyridostigmine (Mestinon), but only four of the ten received it on the moming of surgery, 60-90 minutes before induction of anaesthesia. Three of the ten were receiving chronic corticosteroid therapy and were given supplementation with hydrocortisone $100 \mathrm{mg}$ IV on the morning of surgery. In all patients with myasthenia gravis, the diagnosis had been confirmed preoperatively by electromyography (EMG) or pharmacological testing.

All of the patients received diazepam, 5-10 mg PO for premedication. Anaesthesia was induced with thiamylal, and maintained with nitrous oxide ( 66 per cent) in oxygen and incremental doses of thiamylal and fentanyl. Potent inhaled agents were not used during the study period. Ventilation was controlled with a bag and facemask to maintain end-tidal $\mathrm{CO}_{2}$ within the normal range as measured by a mass spectrometer (Perkin-Elmer Advantage 1100 , Pomona, CA). Train-of-four stimulation was applied to the ulnar nerve at the wrist every ten seconds and the integrated EMG responses of the first dorsal interosseous muscle were recorded using a Datex 221 neuromuscular transmission monitor (Puritan-Bennett Co., Wilmington, MA). Stimulation and recordings were made via surface electrodes. After calibration of baseline EMG response values to 100 per cent by the Datex monitor, patients received a vecuronium bolus dose of 5 or $10 \mu \mathrm{g} \cdot \mathrm{kg}^{-1}$ followed by similar incremental doses together with an infusion of vecuronium, the rate of which was adjusted to replace eliminated drug. ${ }^{8}$ An initial bolus dose and subsequent incremental doses of $5 \mu \mathrm{g} \cdot \mathrm{kg}^{-1}$ were used in the myasthenic patients, and $10 \mu \mathrm{g} \cdot \mathrm{kg}^{-1}$ in the normal controls. Incremental doses were administered and the vecuronium infusion rates increased, when three consecutive equal first responses (T1/C) were observed in the continuously recorded EMG. The vecuronium infusion rate was calculated as follows. Based upon the work of Smith et al. ${ }^{8}$ it was assumed that if a vecuronium bolus dose of $\mathrm{V} \mu \mathrm{g} \cdot \mathrm{kg}^{-1}$ produced a certain degree of depression of $\mathrm{T} 1 / \mathrm{C}$ response, then an infusion rate of $2 \times \mathrm{V}$ $\mu \mathrm{g} \cdot \mathrm{kg}^{-1} \cdot \mathrm{hr}^{-1}$ would be needed to maintain that level of T1/C depression. In the myasthenic patients, a bolus dose of $5 \mu \mathrm{g} \cdot \mathrm{kg}^{-1}$ was administered and, when the T1/C decrement was stable for 20-30 seconds (three equal consecutive $\mathrm{T} 1 / \mathrm{C}$ responses), an incremental dose of vecuronium $5 \mu \mathrm{g} \cdot \mathrm{kg}^{-1}$, was given and an infusion of $(5 \times 2$ $x$ body weight in $\mathrm{kg}$ ) per hour commenced. With each incremental dose of vecuronium, $5 \mu \mathrm{g} \cdot \mathrm{kg}^{-1}$, the vecuronium infusion rate was increased using multiples of the above. Additional doses and infusion rate increases were continued until a 95-99 per cent decrease in T1/C had been achieved. At this time the trachea was intubated and ventilation was controlled. Each patient received between three and eight incremental doses of vecuronium and the total duration of the study period in each patient was between 10 and 15 minutes. Following completion of the dose-response study, anaesthesia and relaxation were maintained with nitrous oxide, fentanyl, and isoflurane. Upon completion of surgery any residual neuromuscular blockade was reversed with incremental doses of edrophonium titrated against the EMG response or until clinical signs of adequate reversal were evident.

Linear regressions were derived for each individual patient between the logit transformation of the neuromuscular blockade (i.e., $(100-\mathrm{T} 1 / \mathrm{C})$ per cent) and the logarithm of the cumulative dose of vecuronium. Only the 


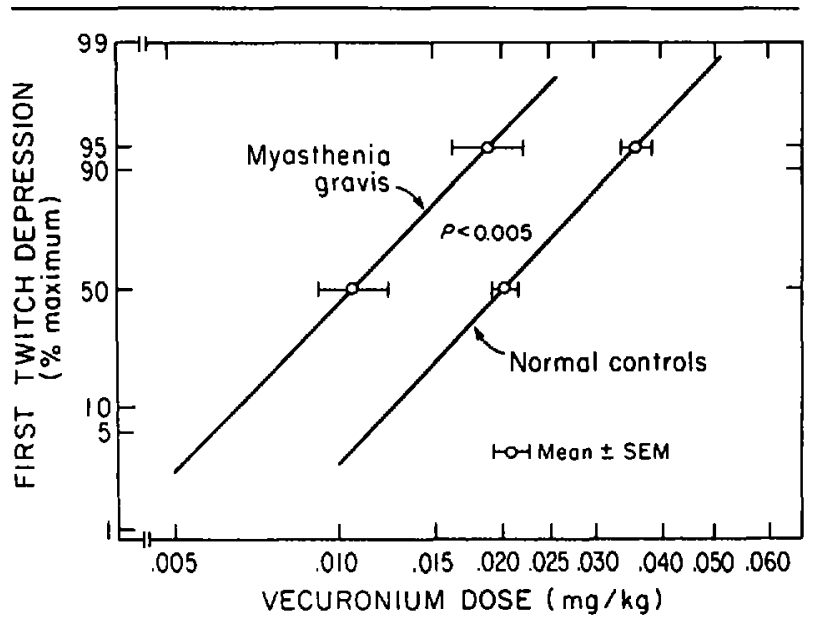

FIGURE 1 Mean log dose-logit response curves for vecuronium in 20 normal controls and ten myasthenic patients obtained using a cumulative dose plus infusion technique. ${ }^{8}$ The equations to the regression lines are: normals: logit response $=4.61 \times \log$ dose +7.93 ; myasthenics: logit response $=4.66 \times \log$ dose +9.16 .

dose administered in bolus form was considered in the derivations of the dose-response regression curves because the amount of vecuronium given by infusion was to replace drug which had been eliminated. ${ }^{8}$ From the individual dose-response curves, each of which was calculated using at least three data points, mean doseresponse curves were constructed for each group. From these curves, the mean effective doses producing 50,90 and 95 per cent block $\left(E_{50}, E_{90}, E D_{95}\right)$ were calculated. The group mean slopes, intercepts and ED values were compared using a Student's $t$ test for unpaired data. A difference was considered to be significant if $P<0.05$.

\section{Results}

No complications were associated with the administration of vecuronium in either group. Residual neuromuscular

TABLE III Mean ED values with 95\% confidence limits for normal and myasthenic patients

\begin{tabular}{llll}
\hline & $\begin{array}{l}\text { Normals } \\
n=20\end{array}$ & $\begin{array}{l}\text { Myasthenics } \\
n=10\end{array}$ & $P$ \\
\hline $\begin{array}{l}\text { ED }_{30} \\
\text { (95\% confidence limits) } \\
\text { Range }\end{array}$ & $\begin{array}{l}19 \\
(17-21) \\
14-33\end{array}$ & $\begin{array}{l}10 \\
(7-14) \\
5-19\end{array}$ & 0.0001 \\
ED & & & \\
$(95 \%$ confidence limits) & $(28-34)$ & $(13-22)$ & 0.0001 \\
Range & $24-52$ & $9-35$ & \\
& & & \\
ED 95 & 36 & 20 & 0.0001 \\
(95\% confidence limits) & $(33-40)$ & $(15-27)$ & \\
Range & $28-61$ & $11-44$ & \\
\hline
\end{tabular}

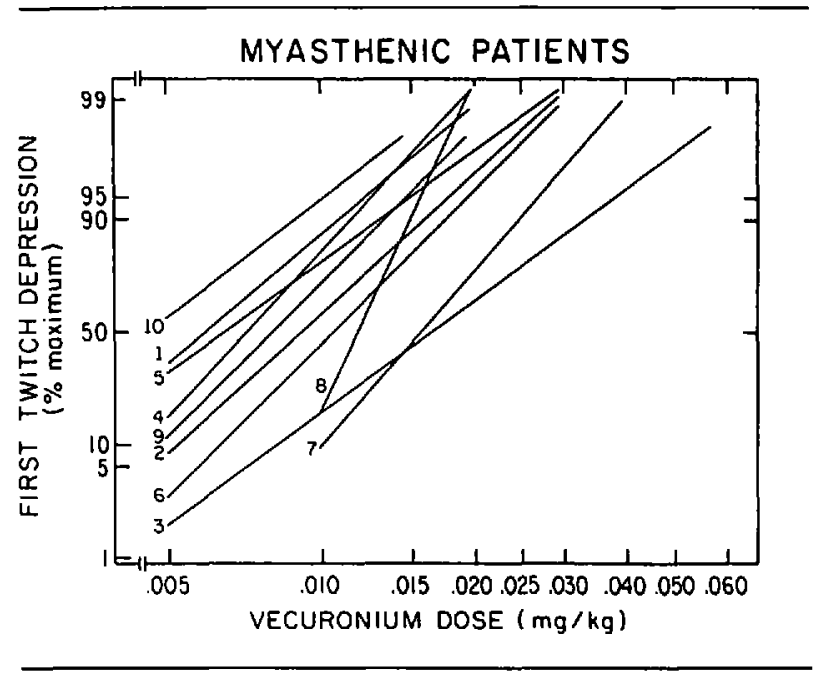

FIGURE 2 Individual log dose-logit response curves for the ten myasthenic patients. The numbers identify the individual patients in Table 1 . patients $2,3,6$ and 10 received preoperative pyridostigmine. Patients 3, 7 and 10 were being chronically treated with prednisone and received hydrocortisone preoperatively (see Table I).

blockade was adequately reversed in all of the patients, whose tracheas were extubated either in the operating room or in the recovery room. None required prolonged postoperative ventilation.

Although the normal and myasthenic patients were not age or sex matched, we found no significant difference between the two groups in mean age or weight. The mean ( \pm SD) ages of the myasthenia and control groups were $41.2( \pm 16.2)$ and $38.5( \pm 13.2) \mathrm{yr}$, respectively, and the weights were $66.4( \pm 13.0)$ and $59( \pm 20) \mathrm{kg}$, respectively. The male:female ratio was 1:9 in the myasthenia group and 4:16 in the control group.

The mean dose-response curves are shown in Figure 1. Compared with the curve in normal patients, the curve for the myasthenic patients was shifted to the left but there were no significant differences between the groups in slope. The myasthenic patients were approximately twice as sensitive as the normal patients, the $\mathrm{ED}_{50}, \mathrm{ED}_{90}$ and $E D_{95}$ values of $10,17,20 \mu \mathrm{g} \cdot \mathrm{kg}^{-1}$ representing 52,55 and 56 per cent of control, respectively (Table III). The differences between these mean values for the myasthenic and normal patient groups were highly significant $(P=$ 0.0001 ). The individual dose-response curves for each of the ten myasthenic patients are shown in Figure 2, and for each of the 20 normal control patients in Figure 3. There was considerable individual variability in the ED values within each group and the ranges of the ED values for the two groups are seen to overlap (Table III, Figures 2, 3).

We failed to demonstrate any difference in sensitivity to vecuronium between those myasthenic patients who had received pyridostigmine (\#s 2, 3, 6 and 10) on the 


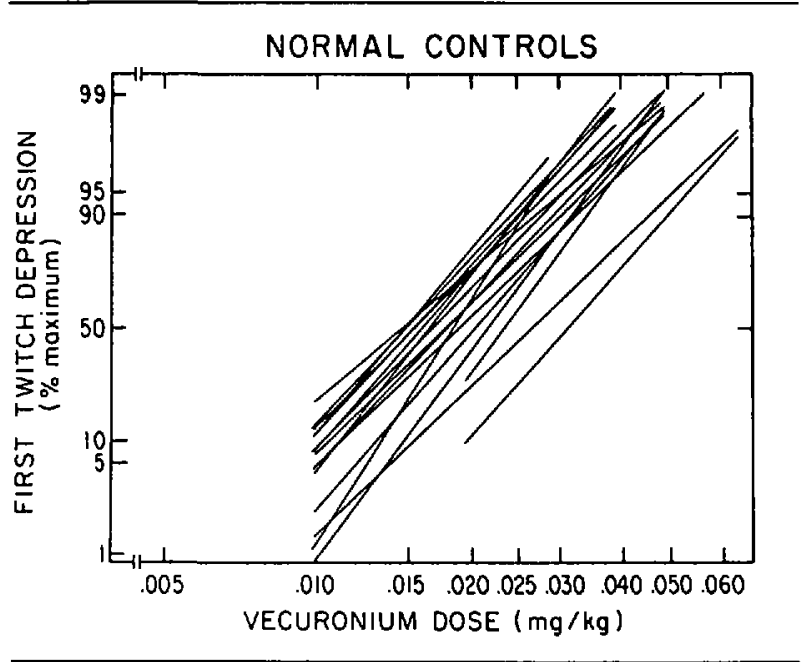

FIGURE 3 Individual log dose-logit response curves for the 20 normal control patients for comparison with Figure 2.

morning of surgery compared with those myasthenic patients who had not. The mean ( \pm SEM) $E D_{50}$ and $E D_{95}$ for patient numbers $2,3,6$ and 10 were $12.0( \pm 3.0)$ and $21.6( \pm 5.6) \mu \mathrm{g} \cdot \mathrm{kg}^{-1}$, respectively, compared with mean $E_{50}$ and $E_{95}$ values of $10.4( \pm 2.0)$ and $15.6( \pm 2.1)$ $\mu \mathrm{g} \cdot \mathrm{kg}^{-1}$, respectively for those patients (\#1, 4, 5, 7, 8, 9) who did not receive pyridostigmine. We also failed to demonstrate any difference in sensitivity to vecuronium between those myasthenic patients receiving chronic steroid therapy $\left(\mathrm{ED}_{50}\right.$ and $\mathrm{ED}_{95}$ of $11.0 \pm 3.7$ and 20.8 $\pm 7.6 \mu \mathrm{g} \cdot \mathrm{kg}^{-1}$, respectively) and those who were not $\left(\mathrm{ED}_{50}, \mathrm{ED}_{95}\right.$ of $11.0 \pm 1.7$ and $17.4 \pm 2.4 \mu \mathrm{g} \cdot \mathrm{kg}^{-1}$, respectively).

\section{Discussion}

There are several reports of the use of vecuronium in patients with myasthenia gravis, ${ }^{3-7}$ on the basis of which the range of values for $E D_{80}-E D_{98}$ is $11-80 \mu \mathrm{g} \cdot \mathrm{kg}^{-1}$. The reasons for this broad range include the small number of patients and individual reports, variability in the perioperative medical management (pryidostigmine, corticosteroids, immunosuppressants) and the variety of methods whereby neuromuscular blockade was assessed in the patients studied.

The single bolus (SB) dose technique is generally considered to be the best method for constructing doseresponse curves. ${ }^{9}$ Use of this technique in myasthenic patients would be difficult, however, because of the small number of patients available for study. In the only other published dose-response study of vecuronium in myasthenic patients, Buzello et al. ${ }^{5}$ used a cumulative doseresponse (CDR) technique and mechanomyographic monitoring of the adductor pollicis. They reported mean (ranges) $\mathrm{ED}_{50}$ and $\mathrm{ED}_{90}$ values of $7(0.3-14) \mu \mathrm{g} \cdot \mathrm{kg}^{-1}$ and $19\left(5-31 \mu \mathrm{g} \cdot \mathrm{kg}^{-1}\right)$, respectively in myasthenics. Their control values were $18(6-28)$ and $44(34-52) \mu \mathrm{g} \cdot \mathrm{kg}^{-1}$. Several groups have shown, however, that the potency estimates for vecuronium using the CDR technique in normal patients overestimate $\mathrm{ED}_{50}$ values by $25-33$ per cent when compared with a SB technique. ${ }^{9-11}$ These authors recommended that the CDR technique not be used for potency determination of muscle relaxants of medium and short duration. ${ }^{9-11}$ The reason for the overestimation of ED values with CDR is that some of the administered drug is redistributed or eliminated before the next incremental dose takes effect. The cumulative dose thus represents both drug producing the observed effect plus that which has been redistributed or eliminated. Therefore, the ED values for vecuronium reported by Buzello et al. ${ }^{5}$ may represent overestimates.

Smith et al. ${ }^{8}$ have introduced a cumulative doseresponse with infusion (CDI) technique to determine the potency of atracurium and vecuronium. They concluded that the use of an infusion to compensate for drug lost by redistribution or elimination resulted in the generation of dose-response curves that were indistinguishable from curves obtained with SB methods. Using the CDI technique and integrated EMG monitoring of the first dorsal interosseous muscle, we obtained mean $\mathrm{ED}_{50}$ and $\mathrm{ED}_{90}$ values for vecuronium of 19 and $31 \mu \mathrm{g} \cdot \mathrm{kg}^{-1}$ in normal patients, compared with the values of 23 and $34 \mu \mathrm{g} \cdot \mathrm{kg}^{-1}$ (SB) and 21 and $36 \mu \mathrm{g} \cdot \mathrm{kg}^{-1}$ (CDI), respectively, reported by Smith et al. ${ }^{8}$

We employed integrated EMG monitoring of the first dorsal interosseous muscle because this technique is simple to apply and it may be used in patients whose arms are adducted during surgery. Although the evoked adductor pollicis mechanomyogram is the response most commonly monitored, Kopman ${ }^{14}$ has reported that the first dorsal interosseous EMG may be used interchangeably with it in determining depth of non-depolarizing neuromuscular blockade. Kopman ${ }^{14}$ also found that calculating the $\mathrm{ED}_{95}$ (of metocurine) from the EMG resulted in a very slight overestimate of that drug's potency. That our ED values (by EMG) were slightly less than those of Smith et al. ${ }^{8}$ (by mechanomyography) is consistent with the observations reported by Kopman. ${ }^{14}$ We therefore believe that the methodology which we used to derive the potency (ED) data for vecuronium is valid.

While the mean $\mathrm{ED}_{50}$ value in our control group (19 $\left.\mu \mathrm{g} \cdot \mathrm{kg}^{-1}\right)$ was essentially the same as that $\left(18 \mu \mathrm{g} \cdot \mathrm{kg}^{-1}\right)$ reported by Buzello et al., our mean value for $\mathrm{ED}_{90}$ (31 $\left.\mu \mathrm{g} \cdot \mathrm{kg}^{-1}\right)$ was much lower than theirs $\left(44 \mu \mathrm{g} \cdot \mathrm{kg}^{-1}\right)$. This difference is probably due to our use of the $C D I$ technique while they used the $C D$ method. In comparing $E_{90}$ values for the myasthenic patients, the difference was much less, our value being $17 \mu \mathrm{g} \cdot \mathrm{kg}^{-1}$ and theirs, 19 
$\mu \mathrm{g} \cdot \mathrm{kg}^{-1}$. Both our study and that of Buzello et al. ${ }^{5}$ found that the $E D_{90}$ for vecuronium in myasthenic patients was approximately 55 per cent of control and, therefore, that patients with myasthenia gravis are approximately twice as sensitive to the neuromuscular blocking effects of vecuronium than are normal patients.

The administration of pyridostigmine to four of our myasthenic patients (\#s 2, 3, 6, 10) on the morning of surgery produced a nonsignificant decrease in their sensitivity to vecuronium, the mean $( \pm S E M) E_{50}$ and $\mathrm{ED}_{90}$ values for these four patients being $12 \pm 3$ and 22 \pm 6 compared with $10 \pm 2$ and $16 \pm 2 \mu \mathrm{g} \cdot \mathrm{kg}^{-1}$, in the other six myasthenic patients (NS), respectively. Compared with the 20 normal patients, these four myasthenic patients were still significantly more sensitive to vecuronium than were normal controls. In our institution, pyridostigmine is administered on the morning of surgery only to those myasthenic patients who require it and who would otherwise be markedly weak and therefore also psychologically uncomfortable. ${ }^{13}$ One cannot therefore assume that pyridostigmine administered preoperatively on the morning of surgery has no effect on the sensitivity to vecuronium, but rather, that without it these four patients might have demonstrated increased sensitivity.

The three myasthenic patients who were receiving chronic therapy with corticosteroids and who received hydrocortisone on the morning of surgery also showed no significant difference from the other seven in their sensitivity to vecuronium (mean $\pm S E M, \mathrm{ED}_{50}, \mathrm{ED}_{95}$, were $11 \pm 4$ and $21 \pm 8 \mu \mathrm{g} \cdot \mathrm{kg}^{-1}$ compared with $11 \pm 2$ and $17 \pm 2 \mu \mathrm{g} \cdot \mathrm{kg}^{-1}$, respectively). In our hospital, corticosteroids are used to treat those patients who have more severe symptoms of generalized myasthenia gravis. ${ }^{13}$ The mechanism whereby corticosteroids improve the clinical condition of patients with myasthenia gravis is thought to be immunosuppression. ${ }^{15}$ The interactions of corticosteroids at the neuromuscular junction in humans is unclear $^{16}$ and, in particular, conclusive data for their effects in patients with myasthenia gravis are not available.

Buzello $e t$ al..$^{5}$ also reported that the recovery times from vecuronium neuromuscular blockade were significantly prolonged in myasthenic patients. We were not able to study this aspect of vecuronium since in our patients isoflurane was used intermittently after the study period as described, and patients with myasthenia gravis have been shown to have an increased sensitivity to the neuromuscular blocking effects of the potent inhaled agents. ${ }^{17}$ Clinically, however, all of our patients demonstrated adequate neuromuscular function following their surgery and anaesthesia.

In conclusion, we have used a cumulative dose plus infusion (CDI) technique and integrated EMG monitoring of the first dorsal interosseous muscle to determine the potency of vecuronium in 20 normal patients and in ten patients with myasthenia gravis. The myasthenic patients were more sensitive to vecuronium, the mean $\mathrm{ED}_{50}, \mathrm{ED}_{90}$ and $\mathrm{ED}_{95}$ being 50,55 and 56 per cent of normal, respectively. Vecuronium may be safely used in myasthenic patients provided that neuromuscular blockade is carefully monitored. There is a wide variability in the $\mathrm{ED}_{90}$ values among myasthenic patients so that if vecuronium is to be used, incremental doses of $5 \mu \mathrm{g} \cdot \mathrm{kg}^{-1}$ titrated against quantified effect are recommended for these patients.

\section{References}

I Azar I. The response of patients with neuromuscular disorders to muscle relaxants: a review. Anesthesiology 1984; 61: 173-87.

2 Brown JC, Charlton JE. A study of sensitivity to curare in myasthenic disorders using a regional technique. $J$ Neurol Neurosurg Psychiatry 1975; 38: 27-33.

3 Pelton $\mathrm{Cl}$. Vecuronium in myasthenia gravis. Anaesthesia 1985; 40: 82-3.

4 Hunter JM, Bell CF, Florence AM, Jones RS, Utting $J E$. Vecuronium in the myasthenic patient. Anaesthesia 1985; 40: 848-53.

5 Buzello W, Noeldge $G$, Krieg N, Brobmann GF. Vecuronium for muscle relaxation in patients with myasthenia gravis. Anesthesiology 1986; 64: 507-9.

6 Eisenkraft JB, Sawhney RK, Papatestas AE. Vecuronium in the myasthenic patient. Anaesthesia 1986; 41: 666-7.

7 Keens SJ, Desmond MJ, Utting JE. Carcinoid syndrome with myasthenia gravis. Anaesthesia 1986; 41: 404-7.

8 Smith CE, Donati F, Bevan DR. Cumulative doseresponse with infusion: a technique to determine neuromuscular blocking potency of atracurium and vecuronium. Clin Pharmacol Ther 1988; 44: 56-64.

9 Fisher DM, Fahey MR, Cronelly R, Miller RD. Potency determination for vecuronium (ORG NC 45): comparison of cumulative and single dose techniques. Anesthesiology 1982; 57: 309-10

10 Ording H, Skovgaard LT, Engbaek J, Viby-Mogensen $J$. Dose-response curves for vecuronium during halothane and neurolept anaesthesia: single bolus vs. cumulative method. Acta Anaesthesiol Scand 1985; 29: 121-4.

11 Gibson FM, Mirakhur RK, Clarke RSJ, Lavery GG. Comparison of cumulative and single bolus dose techniques for determining the potency of vecuronium. Br J Anaesth 1985; 57: $1060-2$.

12 Osserman $K E$, Genkins $G$. Studies in myasthenia gravis: review of a 20 year experience in over 1200 patients. Mount Sinai J Med 1971; 38: 497-537.

13 Eisenkraft $J B$. Myasthenia gravis and thymic surgery anaesthesia considerations. In: Gothard JWW (Ed.). 
Thoracic Anaesthesia. London: Baillièrc-Tindall, 1987:

133-62.

14 Kopman AF. The dose-effect relationship of metocurine: the integrated electromyogram of the first dorsal interosseous muscle and the mechanomyogram of the adductor pollicis compared. Anesthesiology 1988; 68: 604-7.

15 Engel $A G$. Myasthenia gravis and myasthenic syndromes. Ann Neurol 1984; 16: 519-34.

16 Bevan DR, Bevan JC, Donati F. Drug interactions. In: Muscle Relaxants in Clinical Anesthesia. Chicago. Year Book Medical Publishers, Inc., 1988. 400.

17 Eisenkraft JB, Papatestas AE, Sivak $M$. Neuromuscular effects of halogenated agents in patients with myasthenia gravis. Anesthesiology 1984; 61: 3A, A307. 